\title{
Study of Integration of Cattellian and Zuckerman's Models of Personality on Indian Sample
}

\author{
Pradeep $\operatorname{Kumar}^{1 *}$, Umed Singh ${ }^{2}$
}

\section{ABSTRACT}

This study was designed to examine the convergence between Cattellian and Zuckerman's models of personality on Indian subjects. To realize the main objective, 202 students with the age ranging from 19 to 28 years were selected from various PG departments of K.U.K.(Haryana). The subjects were tested with Sixteen Personality Factor Questionnaire (16 PF) and Zuckerman-Kuhlman Personality Questionnaire (ZKPQ) after proper rapport. Obtained data were analysed by using Descriptive Statistics, Pearson's Correlation, and Principal Component Factor Analysis. Obtained correlations depict some overlap between some factors of personality indexed by $16 \mathrm{PF}$ and ZKPQ. Factor Analysis yielded eight factors named as Extroversion/Sociability; Impulsive-Sensation Seeking; Adjustment; Pathemia; Super Ego Strength; Affectothymia; Subduedness v/s Independence; and Activity.

Keywords: Personality, Cattellian Model and AFFM

Personality has been conceptualized from a variety of theoretical perspectives and at various levels of abstraction and breath (John, Hampson \& Goldberg, 1991; \& McAdams, 1997). Each of these levels has made unique contributions to understanding of individual differences in behavior and experience. For the measurement of these theoretical perspectives some personality instruments such as Sixteen Personality Factor Questionnaire (Cattell et al., 1970), Eysenck Personality Questionnaire (Eysenck, 1985), NEO-Personality Inventory (Costa \& McCrae, 1985), Comrey Personality Scales (Comery, 1980), and Zuckerman-Kuhlman Personality Questionnaire (Zuckerman \& Kuhlman, 1993) have been developed. All these instruments bear some common dimensions at higher or lower level as well as differ according to hierarchical structures (Rossier, et al. 2004).

Cattell's early efforts to identify the major structural dimensions of personality began with Allport and Odbert's (1936) classification of adjectives which provided initial structure for the personality lexicon. Aiming at such a structural classification, Cattell (1943) used Allport and

\footnotetext{
${ }^{1}$ Research Scholar, Department of Psychology, K.U. Kurukshetra

${ }^{2}$ Professor, Department of Psychology, K.U. Kurukshetra

*Responding Author

(C) 2016 I P Kumar, U Singh; licensee IJIP. This is an Open Access Research distributed under the terms of the Creative Commons Attribution License (http://creativecommons.org/licenses/by/2.0), which permits unrestricted use, distribution, and reproduction in any Medium, provided the original work is properly cited.
} 


\section{Study of Integration of Cattellian and Zuckerman's Models of Personality on Indian Sample}

Odbert's list as a starting point for his multidimensional model of personality. Cattell (1945) began with the subset of 4500 trait terms (personality sphere) and reduced these trait terms to mere 35 variables using by semantic and empirical clustering procedures. Using this small set of variables, Cattellidentified 12 personality factors which subsequently became part of his 16 Personality Factor Questionnaire (Cattell et al., 1970). Cattell claimed that his factors showed excellent correspondence across different methods such as L-data, Q-data and T-data (Media Indifference Hypothesis). Cattell (1957) also proposed that these 16 primary dimensions are organized into some global factors which provide more comprehensive description of personality structure at higher level (Cattell, 1996). Cattell in his model explored eight global factors of which four have been largely accepted as being major dimensions of personality and were incorporated in earlier versions of 16 PF (Argentero, 1989; Cattell et al., 1970; Krug \& Jones, 1986). But in the fifth and last edition of the $16 \mathrm{PF}$, five global factors have been proposed named as Extraversion (EX); Anxiety (AX); Tough-Mindedness (TM); Independence (IN); and Self-Control (SC) (Cattell \& Cattell, 1995).

Under the trait approach, recently developed Alternative Five Factor Model (AFFM) of personality is psychobiological in origin in which basic personality traits are considered adaptive behavioral solutions which can be seen across species, and are predisposed by inherited biological differences within species (Zuckerman, 1991, 1994, 2005). Alternative Five Factor Model of personality is based on questionnaire whereas the original 'Big Five Model' (FFM: McCrae \& Costa, 1992) is based on lexical analyses of self and others' ratings using adjectives. Zuckerman suggested that questionnaire items describe behaviors, intentions and attitudes. However, the actual development of Alternative Five Factor Model of personality started with factor analytic studies of traits using questionnaire scales that had been used in studies of temperament, genetics, and biological correlates of personality (Zuckerman et al., 1988). For this, in the initial study 46 and in second study 33 scales or subscales selected from 8 different questionnaires of personality or temperament were used (Zuckerman et al, 1991). Factor analyses were conducted and screen test suggested that five factors would be sufficient; therefore, authors conducted factor analyses with rotation for three, five, and seven factors to see what happened to factors going from the broader analyses to the more specific ones. These five factors have been named as Neuroticism-Anxiety (N-Anx); Activity (Act); Sociability (Sy); Impulsive SensationSeeking (Imp-SS); and Aggression-Hostility (Agg-Host). For the measurement of these factors Zuckerman- Kuhlman Personality Questionnaire has been developed (Zuckerman \& Kuhlman, 1993).

Regarding the convergence among various models of personality, some empirical efforts have been made. Byravan and Ramanaich (1995) studied the factorial structure underlying the 16 PFFifth Edition, the NEO- PI, and the Goldberg's “Markers”. Applying Principal Component Factor Analysis with varimax rotation on the five factor scales of the NEO-PI, Five Factor scales

of Goldberg, and of the $16 \mathrm{PF}$; authors were able to extract five factors corresponding to the FFM. Boyle (1987) has studied the factor structure of measures of Cattellian, Comrey's and 
Eysenckian models of personality; and extracted seven separate factors. Rossier et al (2004) investigated the hierarchical structure of the NEO-PI-R and the 16PF-Fifth Edition and found that there was a coherent association among four of the five dimensions measured in these tests at higher level. Similarly, Alternative Five Factor Model has been studied in relation to other models of personality. Zuckerman et al (1993) found the good convergent and discriminant validity within a multi-trait multi-method matrix (Campbell \&Fiske, 1959) in relation to EPQ (Eysenck,1985) and NEO-FFI (Costa \& McCrae, 1985). Kumar and Singh (2011) studied the integration of AFFM, Big Five and Cattellian models of personality and extracted eight factors namely; Neuroticism-Anxiety; Extraversion; Openness; Superego Strength; Self-Concept Control; Carelessness; Independence, and Cool-Realismvs Prodigal Subjectivity. Literature reveals the searching of studies for convergence between Cattellian and Zuckerman's models of personality specially in Indian perspective. So, the present study was planned to examine the relationship between Cattellian and Zuckerman’s models of personality on Indian sample.

\section{METHOD}

Sample:

The sample for the present study was drawn from the Post Graduate students of various PG departments of the Kurukshetra University, Kurukshetra (Haryana). 202 PG students (112 males and 90 females) constituted the sample, with age ranging between 19 to 28 years with the mean age of 23.5 years. Only those students who volunteered to participate in the study were included in the sample.

\section{Measure:}

Following measures were used for the data collection.

(1) Sixteen Personality Factor Questionnaire -Form B (Cattellet al.1970) is 187 items self-rating questionnaire. It indexes16 primary factors, namely: (A) Warmth (B) Scholastic Mental Capacity (C) Ego Strength (D) Dominance (F) Surgency (G) Superego Strength (H) Parmia (I) Tenderminded (L) Protension (M) Autia (N) Shrewdness (O) Guilt Proneness (Q1) Radicalism (Q2) Self- sufficiency (Q3) Self-Concept Control, and (Q4) Ergic Tension. The reliabilities of the $16 \mathrm{PF}$ scales are given in all possible ways and ranging from .63 to .93. The validity of this test has been determined in terms of construct validity i.e. equivalent to .85 .

(2) Zuckerman-Kuhlman Personality Questionnaire (ZKPQ; Zuckerman \& Kuhlman, 1993) consists of 5 content scales and one validity scale i.e. Infrequency scale. ZKPQ includes total 99 dichotomous items (in sentence format and true-false response set) that assess the basic five dimensions of personality incorporated in Alternative Five Factor Model (AFFM). The five scales are described in terms of their contents: Neuroticism-Anxiety (19items); Activity (17 items) comprises two factors i.e. Need for General Activity, and Need for Work Activity; Aggression-Hostility (17 items); Impulsive-Sensation Seeking (19 items) having two factors i.e. Impulsivity, and Sensation Seeking; and Sociability (17 items) containing two factors i.e. Parties and Friends, and Isolation Intolerance. The test-retest reliabilities of the Zuckerman-Kuhlman 
Personality Questionnaire are ranging from .72 to .84 from the American and German samples (Schmitz, 2004). Satisfactory validity has been found, with multi-scale questionnaire for both convergent and discriminant validity within a multi-trait-multi-method matrix (Campbell \& Fiske, 1959).

\section{Procedure}

For data collection all the students were contacted personally in their respective departments and two measures of personality were administered in group settings having 15-20 subjects in each group. These tests were administered in separate sessions. 24 scores (16 from 16 PF, and 8 from ZKPQ) were obtained and subsequently subjected to various statistical analyses.

\section{RESULTS}

Obtained data were analyzed by applying Descriptive Statistics, Pearson' Correlations, and Principal Component Factor Analysis.

Descriptive Statistics depict the data to be almost normal and fulfill the application of Product Moment Method of Correlation.

Inter correlations among 16 measures of personality (16 PF) are in general low ranging from -.66 to .60 with 67 of 120 being significant, of which 36 are positive and 31 are negative. Significant correlations among some factors of personality (16 PF) may be because of their association with some factors at higher order level.

Correlations between 16 factors of $16 \mathrm{PF}$ and eight facet/factor scores of ZKPQ low ranging from -.50 and 60 with 68 of 128 correlations being significant, of which 40 are positive and 28 are negative. Work Effort, a facet of Activity factor of ZKPQ has correlated positively with factors A, B, C, E, G, H, and negatively with O, Q2 and Q4 of 16 PF. General Activity, another facet of Activity has correlated positively with factors B, C, E, H and negatively with I, Q2 and Q4 of 16 PF. Aggression-Hostility has marked significant positive relationship with factors O, Q1, Q2 and Q4; and negative with factors B and C of 16 PF. Impulsivity has corresponded negatively with factors B, C, G, and N; and positively with factors F, O, and Q4 of 16 PF. Sensation Seeking has correlated negatively with factors $\mathrm{B}$, and positively with factors $\mathrm{F}, \mathrm{O}$, and Q4 of $16 \mathrm{PF}$. Neuroticism-Anxiety has marked significant negative relationship with factors A, B, C, E and H, and positive with I, O, Q2 and Q4 of 16 PF. Parties and Friends, a facet of Sociability factor of ZKPQ has marked significant positive relationship with factors A, B, C, E, F, H, L, and negative with factors $\mathrm{N}, \mathrm{O}, \mathrm{Q} 2$ and Q4 of $16 \mathrm{PF}$. Isolation Intolerance, another facet of Sociability has correlated positively with factors A, B, C, E, F, G, H, L, and negative with factors N, O, Q2, and Q4 of 16 PF. Obtained correlations depict substantial amount of variance sharing between two measures (16 PF and ZKPQ). 


\section{Table-1, Inrercorrelations Matrix and Descriptive Statistics}

\begin{tabular}{|c|c|c|c|c|c|c|c|c|c|c|c|c|c|c|c|c|c|c|c|c|c|c|c|c|}
\hline Variables & $\mathbf{A}$ & B & C & $\mathbf{E}$ & $\mathbf{F}$ & G & $\mathbf{H}$ & I & $\mathbf{L}$ & $\mathbf{M}$ & $\mathbf{N}$ & $\mathbf{O}$ & Q1 & Q2 & Q3 & Q4 & WE & GA & $\begin{array}{l}\text { Agg- } \\
\text { Host }\end{array}$ & Imp & SS & $\begin{array}{l}\text { N- } \\
\text { Anx }\end{array}$ & PF & II \\
\hline $\mathrm{A}$ & $\mathrm{XX}$ & 16 & 25 & 34 & 28 & -13 & 30 & 08 & 21 & 14 & -32 & -18 & -07 & -29 & 03 & -29 & 19 & 12 & 02 & -09 & -07 & -18 & 30 & 26 \\
\hline B & & $\mathrm{XX}$ & 06 & 31 & 13 & 26 & 16 & 03 & 06 & -10 & 01 & -31 & 22 & -22 & 10 & -16 & 26 & 22 & -17 & -20 & -17 & -18 & 26 & 27 \\
\hline $\mathrm{C}$ & & & $\mathrm{XX}$ & 24 & 42 & -05 & 49 & -25 & -05 & 20 & -15 & -66 & 15 & -27 & 30 & -64 & 15 & 22 & -28 & -14 & -05 & -49 & 29 & 29 \\
\hline $\bar{E}$ & & & & $\mathrm{XX}$ & 37 & 00 & 39 & 06 & 20 & 14 & -19 & -23 & 28 & -46 & -09 & -07 & 15 & 15 & -01 & -09 & -10 & -29 & 31 & .28 \\
\hline $\mathrm{F}$ & & & & & $\mathrm{XX}$ & -14 & 45 & -25 & 26 & 23 & -31 & -31 & 19 & -54 & 16 & -25 & 11 & 13 & -04 & 25 & 26 & -17 & 45 & 39 \\
\hline $\bar{G}$ & & & & & & $\mathrm{XX}$ & -05 & 05 & 03 & 04 & 20 & -09 & 09 & -06 & 10 & 00 & 16 & -02 & -08 & -16 & -10 & 02 & 07 & 14 \\
\hline $\mathrm{H}$ & & & & & & & $\mathrm{XX}$ & -01 & 23 & 07 & -30 & -51 & 08 & -45 & 06 & -41 & 29 & 32 & -06 & 00 & 05 & -46 & 47 & 45 \\
\hline I & & & & & & & & XX & 08 & -04 & 10 & 14 & 04 & 23 & 02 & 23 & $\begin{array}{c}-06 \\
\end{array}$ & -15 & 30 & 07 & 02 & 23 & -20 & -09 \\
\hline $\mathrm{L}$ & & & & & & & & & XX & 08 & -24 & -04 & 04 & -32 & -01 & 02 & 09 & 10 & 01 & 07 & 08 & 04 & 14 & .19 \\
\hline M & & & & & & & & & & $\mathrm{XX}$ & -07 & -12 & -05 & -06 & 07 & -26 & -02 & -03 & -12 & -07 & -05 & -13 & 10 & 14 \\
\hline $\mathrm{N}$ & & & & & & & & & & & XX & 09 & 01 & 30 & 09 & 12 & -11 & -09 & -06 & -17 & -01 & 13 & -28 & -15 \\
\hline $\bar{O}$ & & & & & & & & & & & & XX & -18 & 40 & -14 & 60 & -21 & -13 & 45 & 29 & 18 & 60 & -41 & -41 \\
\hline Q1 & & & & & & & & & & & & & $\mathrm{XX}$ & $\begin{array}{l}-01 \\
\end{array}$ & 07 & -01 & -04 & $\begin{array}{l}-03 \\
\end{array}$ & 16 & $\begin{array}{l}-01 \\
\end{array}$ & 01 & 07 & -01 & .02 \\
\hline Q2 & & & & & & & & & & & & & & $\mathrm{XX}$ & 12 & 26 & -30 & -19 & 29 & -01 & -00 & 36 & -50 & -44 \\
\hline Q3 & & & & & & & & & & & & & & & $\mathrm{XX}$ & -26 & 02 & 11 & -08 & $\begin{array}{l}-03 \\
\end{array}$ & 02 & -05 & -06 & .04 \\
\hline$\overline{\mathrm{Q} 4}$ & & & & & & & & & & & & & & & & XX & -22 & -28 & 40 & 36 & 27 & 58 & -25 & -27 \\
\hline$\overline{W E}$ & & & & & & & & & & & & & & & & & $\mathrm{XX}$ & 30 & -17 & -04 & 02 & -30 & 37 & 28 \\
\hline$\overline{\mathrm{GA}}$ & & & & & & & & & & & & & & & & & & $\mathrm{XX}$ & -16 & -04 & -02 & -21 & 12 & 14 \\
\hline Agg-Host & & & & & & & & & & & & & & & & & & & $\mathrm{XX}$ & 29 & 22 & 44 & -19 & -20 \\
\hline Impulsivity & & & & & & & & & & & & & & & & & & & & $\mathrm{XX}$ & 70 & 32 & 06 & 06 \\
\hline $\begin{array}{l}\text { Sen. } \\
\text { Seeking }\end{array}$ & & & & & & & & & & & & & & & & & & & & & $\mathrm{XX}$ & 26 & 02 & 05 \\
\hline N-Anx & & & & & & & & & & & & & & & & & & & & & & $\mathrm{XX}$ & -39 & -33 \\
\hline $\begin{array}{l}\text { Parties \& } \\
\text { Friends }\end{array}$ & & & & & & & & & & & & & & & & & & & & & & & $\mathrm{XX}$ & 67 \\
\hline Iso. Int. & & & & & & & & & & & & & & & & & & & & & & & & $\mathrm{XX}$ \\
\hline Mean & 9.27 & 8.49 & 13.51 & 13.07 & 12.53 & 12.75 & 14.15 & 10.45 & 10.05 & 10.86 & 9.98 & 10.93 & 9.94 & 9.89 & 11.43 & 10.18 & 5.38 & 4.98 & 7.59 & 4.46 & 4.48 & $\begin{array}{l}6.88 \\
\end{array}$ & 4.43 & 4.60 \\
\hline SD & 2.83 & 2.28 & 4.18 & 3.44 & 5.06 & 2.67 & 5.04 & 3.60 & 2.90 & 2.93 & 2.63 & 3.92 & 2.68 & 3.82 & 2.93 & 5.21 & 1.20 & 1.17 & 2.46 & 1.61 & 1.54 & 4.32 & 1.57 & 1.56 \\
\hline SK & .22 & -.71 & .24 & .04 & .19 & .07 & -.21 & .02 & .11 & .27 & .43 & -.08 & .08 & -.25 & -.10 & .21 & .26 & -.10 & -.28 & -.00 & -.01 & .42 & .21 & -.00 \\
\hline $\mathrm{Ku}$ & -.45 & -.05 & .17 & -.47 & -.17 & -.22 & -.50 & -.87 & -.27 & -.68 & -.06 & -.62 & -.45 & -.23 & -.16 & -.51 & .17 & -.06 & -.38 & .00 & .01 & -.87 & -.74 & -.61 \\
\hline
\end{tabular}

Note: Decimal points are omitted in intercorrelations matrix and coefficients in boldface are significant. $\mathrm{r}=.14 \mathrm{p}<.05 ; \mathrm{r}=.18 \mathrm{p}<.01$

Intercorrelations among eight facets/factors of ZKPQ are ranging between -.39 and .70 with 19 of 28 being significant, of which 11 are positive and 8 are negative. Significant correlations among some scales of ZKPQ may be because of their association with some factors of personality at higher-order level as in case of NEO-PI-R.

Though the bivariate correlations provide significant information about the variables, yet is considered suggestive. The true relationship is eclipsed by some underlying factors, which need to be explored. So, for it $24 \times 24$ intercorrelations matrix was subjected to Principal Component 
Factor Analysis with varimax rotation (Kaiser, 1958) and eight factors were extracted with Eigenvalue above 1.00 criterion which have explained $66.63 \%$ of variance.

Table-2, Rotated Factor Matrix

\begin{tabular}{|c|c|c|c|c|c|c|c|c|}
\hline Variables & I & II & III & IV & $\mathbf{V}$ & VI & VII & VIII \\
\hline A & .358 & -.188 & .149 & .412 & -.332 & .351 & -.077 & .074 \\
\hline $\mathrm{B}$ & .295 & -.235 & -.007 & .102 & .385 & .077 & .364 & .412 \\
\hline $\mathrm{C}$ & .432 & -.113 & .662 & -.097 & -.241 & -.196 & .194 & -.012 \\
\hline $\mathrm{E}$ & .407 & -.197 & -.087 & .372 & -.127 & .122 & .508 & .039 \\
\hline $\mathrm{F}$ & .441 & .336 & .283 & .403 & -.209 & -.248 & .323 & -.083 \\
\hline $\mathrm{G}$ & .119 & -.090 & .008 & .075 & .792 & .033 & .035 & .020 \\
\hline $\mathrm{H}$ & .634 & .020 & .289 & .129 & -.277 & .099 & .158 & .224 \\
\hline I & -.074 & -.007 & -.038 & -.004 & .111 & .846 & .011 & -.046 \\
\hline $\mathrm{L}$ & .056 & .072 & -.030 & .770 & .038 & .021 & .038 & .087 \\
\hline $\mathrm{M}$ & .119 & -.115 & .361 & .402 & .060 & -.048 & -.181 & -.542 \\
\hline $\mathrm{N}$ & -.254 & -.051 & .071 & -.384 & .530 & .006 & .000 & -.064 \\
\hline $\mathrm{O}$ & -.617 & .301 & -.411 & .136 & -.005 & .189 & -.233 & .000 \\
\hline Q1 & -.032 & .038 & .098 & -.029 & .088 & .035 & .866 & -.030 \\
\hline $\mathrm{Q} 2$ & -.605 & .029 & .104 & -.428 & .070 & .328 & -.145 & -.115 \\
\hline Q3 & -.139 & .108 & .767 & .041 & .234 & .084 & .025 & .109 \\
\hline Q4 & -.375 & .393 & -.635 & .015 & .144 & .191 & .063 & -.078 \\
\hline WE & .461 & -.010 & .023 & .064 & .154 & .035 & -.188 & .534 \\
\hline GA & .042 & -.039 & .271 & .206 & -.097 & -.167 & -.029 & .737 \\
\hline AGGHOST & -.261 & .361 & -.176 & .020 & -.197 & .561 & .213 & -.064 \\
\hline IMP & .035 & .877 & -.100 & .032 & -.123 & .050 & -.035 & -.012 \\
\hline SS & .049 & .867 & .037 & -.012 & -.024 & .004 & -.021 & .012 \\
\hline NANX & -.584 & .422 & -.246 & .140 & .162 & .225 & .051 & -.116 \\
\hline II & .834 & .082 & -.054 & .117 & .022 & -.095 & -.018 & .040 \\
\hline PF & .778 & .104 & .070 & .148 & .187 & -.002 & -.016 & -.014 \\
\hline$\%$ of Var. & 23.60 & 11.07 & 7.31 & 6.28 & 6.18 & 5.08 & 4.84 & 4.27 \\
\hline Eigen. & 5.67 & 2.66 & 1.76 & 1.51 & 1.48 & 1.22 & 1.16 & 1.02 \\
\hline
\end{tabular}

Note: Significant loadings are in bold face; last two rows of the table showing \% of variance and Eigenvalues for each of the rotated factor respectively.

Factor-I highly loads on Isolation Intolerance and Parties and Friends facets of Sociability of ZKPQ with respective loadings of .834 and .778 depicting positive association between them. Work Effort, a facet of Activity factor of ZKPQ has also marked positive loading of .461; and Neuroticism-Anxiety one of five factors of ZKPQ has marked negative loading of -.584 depicting some positive association between 


\section{Study of Integration of Cattellian and Zuckerman's Models of Personality on Indian Sample}

Sociability and Activity factors and their inverse relationship with Neuroticism-Anxiety. It may be because of existence of higher order factor of personality in ZKPQ. Overall, markers from ZKPQ are indicative of positive affect. Factors A, C, E, F, and H of 16 PF have marked significant positive loadings on this factor whereas factors O, Q2 and Q4 of 16 PF have marked significant negative loadings of -.617, -.605, and -.374. Factorial combination of these markers of 16 PF are indicative of Exvia, a second order factor of personality in 16 PF (Cattell et. al, 1970).In view of the nature of markers from ZKPQ and $16 \mathrm{PF}$, this factor in conveniently named as Extroversion/Sociability. Here, this factor depicts the compatibility between Extraversion, a second order factor of personality in Cattellian model, and Sociability factor of Alternative Five Factor Model of personality by Zuckerman and Kuhlman. It has explained $23.60 \%$ of total variance.

Factor-II has yielded high positive loadings of .877 and .867 on Impulsivity and Sensation Seeking facets of Impulsive-Sensation Seeking factor of ZKPQ followed by AggressionHostility (.361) and Neuroticism-Anxiety (.422). Obtained structure clearly replicates ImpulsiveSensation Seeking factor of AFFM, and also hints the possibility of an higher-order factor of personality from ZKPQ, as the measures of Aggression-Hostility and Neuroticism-Anxiety have marked positive association with Impulsive-Sensation Seeking. It is understandable in the light of earlier findings (Zuckerman et al, 1993) in which Aggression-Hostility and ImpulsiveSensation Seeking were found to be positively correlated with Psychoticism of EPQ. Here factors F, O, and Q4 of 16 PF have also marked significant loadings of .336, .301, and .393 respectively which are slight indicants of Anxiety, a second-order factor of personality from 16 PF (Cattell et al, 1970). Nature of markers between both ZKPQ and 16 PF hereby suggests it to be a factor of Impulsive-Sensation Seeking. Hence, the present structure depicts some overlap between Impulsive-Sensation Seeking factor of AFFM, and Anxiety, a second-order factor of Cattellian model, and has explained $11.07 \%$ of total variance.

Factor-III positively loads on factors C, M and Q3 of 16 PF with respective loadings of .662, .361 and .767; and negatively on $\mathrm{O}(-.411)$ and Q4 (-.635). Factors $\mathrm{F}$ and $\mathrm{H}$ have also marked some considerable positive loadings on this factor. Obtained structure is indicative of adjustment. General Activity, a facet of Activity factor, and Neuroticism-Anxiety, a factor of ZKPQ have also marked considerable positive and negatively loadings respectively on this factor depicting positive association of adjustment with General Activity and negative with Neuroticism-Anxiety. It has explained $7.31 \%$ of total variance.

Factor-IV has been defined by factors A, E, F, L, and M with positive loadings ranging from .372 to .770; and by $\mathrm{N}$ and Q2 of $16 \mathrm{PF}$ with negative loadings of -.384 and -.428 respectively. In Cattellian model such factorial combination is named as Pathemia. It is worth noting that none of the markers of five factors of personality of ZKPQ has marked association with this factor. It has explained $6.28 \%$ of total variance. 
Factor-V has marked high positive loadings of .792 on factor G of 16 PF followed by factor $\mathrm{N}$ (.530), B (.385); and negative loadings of -.332 on factor A. Obtained structure partially replicates one of the second-stratum factors of personality in Cattellian model i.e. Low Super Ego Strength v/s High Super Ego Strength. This structure is indicative of higher superego strength. None of the facets/factors of ZKPQ has marked substantial association with this factor. It has accounted for $6.18 \%$ of total variance.

Factor-VI mainly loads on three factors of $16 \mathrm{PF}$ vizI, A, and Q2 with respective loadings of .846, .351, and .328. Aggression-Hostility of ZKPQ has also marked significant positive loading of .561 depicting positive association with factors I, A, and Q2 of 16 PF. Obtained structure portrays an aggressive person to be affectothymia, tender minded, and preferring own decisions. It has explained $5.08 \%$ of total variance. It has explained $5.08 \%$ of total variance.

Factor-VII highly loads on factor Q1 of 16 PF with the loading of .866 followed by E (.508), B (.364) and F (.323). It partially replicates one of the second-stratum factors (Subduedness v/s Independence) of personality of Cattellian model. It is worth noting that none of the scales of Alternative five factors has marked association with this factor. It accounts for $4.84 \%$ of variance.

Factor-VIII positively loads on General Activity and Work Effort facets of Activity factor of ZKPQ with respective loadings of .737 and .534. Factor B of 16 PF has marked positive loading of .412 and factor $M$ has marked negative loading of -. 542 on this factor. It replicates the Activity factor of Alternative Five Factor Model. Obtained structure depicts positive association of Activity factor of AFFM with factor B and negative with factor M of 16 PF. It has accounted for $4.27 \%$ of total variance.

\section{CONCLUSION}

Based on the findings of the present study it can be inferred that no one-to-one relationship between factors of Cattellian model and AFFM can be ascertained. Direct correspondence has been found between Sociability of AFFM, and Extraversion; and between Impulsive-Sensation Seeking and Anxiety. The relationship between the personality factors of two models is complex and multidimensional. The present findings can not be considered generalizable. More large scale studies are required to verify the compatibility between two models of personality.

\section{REFERENCES}

Allport, G. W., \&Odbert, H. S. (1936). Trait-names: A psycho-lexical study. Psychological Monograph, 47 (1, Whole No. 211), 1-171.

Argentero, P. (1989). Second-Order Factor Structure Of Cattell's 16 Personality Factor Questionnaire. Perceptual and Motor Skills: Volume 68, Issue , pp. 1043-1047.

Boyle, G.J. (1987). Review of the (1985) "Standards for educational and psychological testing: 
Campbell, D.T., \& Fiske, D.W. (1959).Convergent and discriminate validation by the multitraitmultimethod matrix. Psychol. Bull, 58:81-105.

Cattell, R. B. (1943). The description of personality: Basic traits resolved into clusters. Journal of Abnormal and Social Psychology, 38, 476-506.

Cattell, R. B. (1945). The description of personality: Principles and findings in a factor analysis. American Journal of Psychology, 58, 69-90.

Cattell, R. B. (1957).Personality and motivation structure and measurement. Yonkers-onHudson, NY: World Book.

Cattell, R. B. (1996). 'The fallacy of five factors in the personality sphere', The Psychologist, 8(5): 207-8.

Cattell, R. B., Cattell, A. K., \& Cattell, H. E. P. (1993).16PF Fifth Edition Questionnaire. Champaign, IL: IPAT.

Cattell, R. B., Eber, H. W. \& Tatsuoka, M. M. (1970).Handbook for the Sixteen Personality Factor Questionnaire. Champaign, IL: Institute for Personality and Ability Testing.

Comrey, A. L. (1970). Manual for the Comrey Personality Scales. San Diego, CA: Educational and Industrial Testing Service.

Costa, P. T., \& McCrae, R. R. (1985).The NEO Personality Inventory manual. Odessa, FL: Psychological Assessment Resources.

Eysenck. H. J., \&Eysenck, M. W. (1985). Personality and Individual Differences: A natural science approach. New York: Plenum Press.

Krug, S. E. \& Jones, E. F. (1986). A large scale cross-validation of second order personality structure defined by the 16 PF', Psychological Reports, 59 (2): 683-93.

Kumar, P. \& Singh, U. (2011).A Study of Integration of Alternative Five, Big Five and Cattellian Models of Personality. Unpublished Dissertation.

John, O. P., Hampson, S. E., \& Goldberg, L. R. (1991). Is there a basic level of personality description? Journal of Personality and Social Psychology, 60, 348-361.

Kaiser, H. F. (1958): "The varimax criterion for analytic rotation in factor analysis." Psychometrika23: 187-200.

MacAdams, D. P. (1997).A conceptual history of personality psychology. In R. Hogan, J. Johnson, \& S. Briges (Eds.), Handbook of Personality Psychology (pp. 3-39). San Diego: Academic Press.

McCrae, R. R., \& John, O. P. (1992).An introduction to the five-factor model and its applications.Journal of Personality, 60, 175-215.

Rossier J., Meyer de Stadelhofen F., Berthoud S. (2004).The hierarchical structures of the NEO PI-R and the 16 PF 5.Eur. J. Psychol. Assess.20, 27-3810.1027/1015-5759.20.1.27 [Cross Ref]

Schmitz, P.G. (2004). On the alternative five factor model: Structures and Correlates, In R.M. Stelmack (ed). On the Psychobiology of Personality: Essays in Honor of Marvin Zuckerman. Amsterdam: Elsevier, pp.65-87.

Zuckerman, M. (1991).Psychobiology of personality. New York: Cambridge University Press. 
Zuckerman,M. (1994). Behavioural expressions and biosocial bases of sensation seeking. New York: Cambridge University Press.

Zuckerman, M. (2005).Psychobiology of personality (Second edition, revised and updated).New York: Cambridge University Press.

Zuckerman, M., \& Kuhlman, D.M. (1993).Norms for the Zuckerman-Kuhlman Personality Questionnaire (ZKPQ).Unpublished manuscript.

Zuckerman, M., Kuhlman, D. M., \& Camac, C. (1988). What lies beyond E and N? Factor analyses of scales belied to measure basic dimensions of personality. Journal of Personality and Social Psychology, 54, 96-107. 